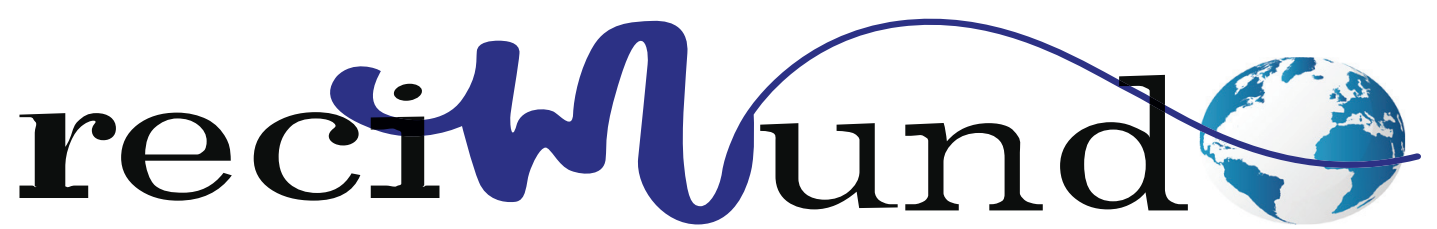

Revista Científica Mundo de la Investigación y el Conocimiento

DOI: 10.26820/recimundo/4.(1).esp.marzo.2020.236-249

URL: http://recimundo.com/index.php/es/article/view/797

EDITORIAL: Saberes del Conocimiento

REVISTA: RECIMUNDO

ISSN: 2588-073X

TIPO DE INVESTIGACióN: Artículo de Revisión

CÓDIGO UNESCO: 3205 Medicina Interna

PAGINAS: $236-249$

\title{
Diagnóstico y tratamiento de cáncer de vesícula biliar
}

\section{Diagnosis and treatment of gallbladder cancer}

Diagnóstico e tratamento do câncer de vesícula biliar

María Isabel Hernández Salcedo'; Katherine Elizabeth Almeida Barba2; Andrea Michelle Castillo González; Adrián Ricardo Freire Sandoval ${ }^{4}$

\section{RECIBIDO: 20/11/2019 ACEPTADO: 29/01/2020 PUBLICADO: 05/03/2020}

1. Especialista en Cirugía General; Médico General; Investigadora Independiente; Quito, Ecuador; mariaisabelhernandezsalcedo@gmail.com; (iD) https://orcid.org/0000-0001-7697-8281

2. Médico; Investigadora Independiente; Quito, Ecuador; kathyelialb@gmail.com; (D) https://orcid.org/0000-00024404-3059

3. Médico; Investigadora Independiente; Quito, Ecuador; andreikicastillo@gmail.com; (D) https://orcid.org/00000001-5569-5952

4. Médico; Investigadora Independiente; Guayaquil, Ecuador; adrixnf@gmail.com; (D) https://orcid.org/00000002-5591-9386

CORRESPONDENCIA

María Isabel Hernández Salcedo

mariaisabelhernandezsalcedo@gmail.com

Quito, Ecuador 


\section{RESUMEN}

El cáncer de vesícula biliar (CVB) afecta a una patología que tiene baja frecuencia en Sudamérica, excepto en Chile, obteniendo la más alta incidencia del mundo. Es una enfermedad que, lamentablemente sólo presenta síntomas generalmente cuando ya se encuentra en etapas avanzadas. Siendo, la principal causa de muerte por cáncer en la población femenina. Entre los factores de riesgo asociados están la obesidad, la edad, la colelitiasis, infecciones bacterianas y algunos agentes genéticos que ocupan una posición importante en su etiopatogenia. Con respecto, al diagnóstico se obtiene por imágenes como la Ultrasonografía (US), la Tomografía Computada (TC), la Resonancia Nuclear Magnética (RNM) son de gran utilidad. Se utilizan marcadores tumorales como parte del diagnóstico, que pueden servir de ayuda en el seguimiento y el pronóstico en algunos casos. El tratamiento de elección en las primeras etapas es la cirugía, considerándose que, esta enfermedad se pesquisa como hallazgo de colecistectomías de rutina por colelitiasis.

Palabras clave: Cáncer de vesícula biliar, Cáncer temprano, vesícula biliar, imágenes diagnósticas, estadio de la enfermedad, tratamiento, colecistectomía, colelitiasis.

\section{ABSTRACT}

Gallbladder cancer (CVB) affects a pathology that has a low frequency in South America, except in Chile, obtaining the highest incidence in the world. It is a disease that, unfortunately, only presents symptoms generally when it is already in advanced stages. Being, the main cause of cancer death in the female population. Among the associated risk factors are obesity, age, cholelithiasis, bacterial infections and some genetic agents that occupy an important position in its etiopathogenesis. With respect, the diagnosis is obtained by images such as Ultrasonography (US), Computed Tomography (CT), Magnetic Nuclear Resonance (MRI) are very useful. Tumor markers are used as part of the diagnosis, which can help with monitoring and prognosis in some cases. The treatment of choice in the early stages is surgery, considering that this disease is investigated as a finding of routine cholecystectomies for cholelithiasis.

Keywords: Gallbladder cancer, Early cancer, gallbladder, diagnostic images, disease stage, treatment, cholecystectomy, cholelithiasis.

\section{RESUMO}

O câncer de vesícula biliar (CVB) afeta uma patologia de baixa frequência na América do Sul, exceto no Chile, obtendo a maior incidência no mundo. É uma doença que, infelizmente, só apresenta sintomas geralmente quando já está em estágios avançados. Sendo, a principal causa de morte por câncer na população feminina. Entre os fatores de risco associados estão obesidade, idade, colelitíase, infecções bacterianas e alguns agentes genéticos que ocupam uma posição importante em sua etiopatogenia. Com respeito, o diagnóstico é obtido por imagens como ultrassonografia (US), tomografia computadorizada (tomografia computadorizada), ressonância nuclear magnética (ressonância nuclear magnética). Marcadores tumorais são usados como parte do diagnóstico, o que pode ajudar no monitoramento e prognóstico em alguns casos. O tratamento de escolha nos estágios iniciais é a cirurgia, considerando que esta doença é investigada como um achado de colecistectomias de rotina para colelitíase.

Palavras-chave: Câncer da vesícula biliar, Câncer inicial, vesícula biliar, imagens de diagnóstico, estágio da doença, tratamento, colecistectomia, colelitíase. 


\section{Introducción}

Las neoplasias de la vía biliar son infrecuentes y se asocian a una alta mortalidad y mal pronóstico. El CVB representa el 3\% de los tumores malignos, dentro de las neoplasias malignas del aparato digestivo, obtiene el quinto lugar en orden de frecuencia después de estómago, colon, recto y esófago, (Potente \& et al, 1994) (Wanebo \& al et, 1993). El acontecimiento de CVB es muy variable de acuerdo a las regiones geográficas y los grupos étnico-raciales, cuyo margen de ocurrencia anual oscila entre 2-13/100.000 habitantes, (Diehl, Epidemiology of gallbladder cancer: a synthesis of recent data, 1990).

Con referencia, la edad más común donde se presenta el CVB se encuentra entre los 65-75 años, estimándose un aproximado del $90 \%$ de los pacientes tienen más de 50 años, (Marijuán \& et al, 1992). Así mismo, el sexo femenino es más frecuente, con proporciones variables que oscilan entre 1,5 y 11:1 (Gers, 1961), se ha justificado la importancia en la mayor recurrencia de colelitiasis en la población femenina, factor que se relaciona con frecuencia al CVB. El cáncer vesicular en etapas avanzadas cuya mortalidad es eminente, lo ideal es diagnosticarlo y tratarlo en una etapa temprana de la enfermedad.

Debe señalarse que, las tasas con mayor incidencia se registran en Chile, habitantes del noreste de Europa, Israel, indios americanos y americanos de origen mexicano; actualmente se ha notificado que el CVB es la principal causa de muerte por cáncer entre las mujeres de Chile (Roa \& et al, DNA content in gallbladder carcinoma: a flow cytometric study of 96 cases, 1993). Las tasas más bajas se han observado en habitantes de raza negra de Zimbawe y América y en países como España e India.

De esta manera, la enfermedad afecta fundamentalmente a una población con facto- res de riesgo: colecistolitiasis, edad avanzada, obesidad y sexo femenino. Resulta claro que, a pesar de los avances tecnológicos modernos, el diagnóstico suele ser Iento; ocasionalmente es un hallazgo casual durante la colecistectomía o es descubierto mediante el examen anatomopatológico de la pieza operatoria. (Cubillos, Duarte, Quappe, \& et al, Cáncer de vesícula biliar. Estudio anatomo clínico de 100 casos, 1987). Los síntomas del cáncer vesicular son inespecíficos y desgraciadamente las primeras manifestaciones aparecen cuando ya es incurable; ni los estudios de laboratorios, ni la exploración física son sugerentes en estadios iniciales, de ahí que un alto porcentaje se presente en fases avanzadas. (Arroyo, GETICS Cáncer de vesícula biliar Artículo de revisión Grupo de Estudio, Tratamiento e Investigación del Cáncer del Sur). El diagnóstico tardío reduce las posibilidades de una terapéutica quirúrgica, cerrando completamente el pronóstico. (Malvenda, 2002). Así mismo, la cirugía es el único tratamiento curativo para el cáncer de la vesícula biliar. En los estadios muy precoces - detectados por el estudio rutinario - la colecistectomía es considerada suficiente a los fines curativos. (Shimada, Endo, Togo, \& et al, 1997). Aunque, cuando surge la sospecha intraoperatoria y se hace el diagnóstico por congelación es recomendable la colecistectomía ampliada. (Todoroki, Kawamoto, Takahashi, \& et al, 1999).

La colecistectomía por litiasis es una cirugía comun en cualquier centro hospitalario, esta razón es de interés, para el cirujano general y el cirujano oncólogo sobre todo en la comprensión de esta patología y la pauta terapéutica más recomendable.

Debe señalarse que, el pronóstico de vida en todas las etapas del CVB es cerca al $5 \%$. La vida media en los pacientes diagnosticados incidentalmente es de 26,4 meses (Chan, y otros, 2003). El objetivo de esta revisión es compendiar el conocimiento vigente existente en esta patología altamente 
prevalente, además, evaluar las diversas clínicas y anátomo-patológicas de estudios recientes sobre pacientes con carcinoma de la vesícula biliar.

\section{Metodologia}

La revisión que se presenta en este artículo es de tipo documental sobre el diagnóstico y tratamiento del cáncer de vesícula biliar, la recopilación de la información se ha realizado a través de una investigación con análisis bibliográfico y de estudios recientes encontrados a través de medios Electrónicos, en donde hay disponible basto material de consulta. Aquí se consideran los aportes más importantes de ciertos autores, con el objetivo de dejar abierta la investigación para futuros casos que den soporte a nuevos estudios.

\section{Resultados}

El cáncer de vesícula biliar (CVB) es una patología infrecuente en el mundo y altamente letal. Maximillian de Stoll en 1777, realizo la descripción por primera vez, en la famosa Vienna Clinic. Luego, Keen en 1891 ejecuto la primera resección, separando el carcinoma del órgano. Seguidamente en 1978, Piehler y Crichlow elaboro el primer estudio reportado de CVB demostrando un 5\% de sobrevida (SV) en 5835 casos analizados (Roa, y otros, 1994). Para el año 1931, Garretón Silva resalta la alta frecuencia de CVB al describir que en una muestra de 350 pacientes observados con colecistitis aguda, 4 de ellos presentaban afección de una transformación maligna (De Aretxabala X. , Cáncer de vesícula biliar, 2005).

Las neoplasias de la vía biliar están asociados a una mortalidad alta, por su diagnóstico tardío el pronóstico no es alentador. Tiene el quinto lugar de frecuencia dentro de las neoplasias malignas del aparato digestivo (Andrew, y otros, 2010). Representando el 3\% de los tumores malignos. El cáncer de vesícula biliar es el más común de todos los tumores biliares (Lazcano-Ponce, y otros, 2001).

La afectación del cáncer de vesícula biliar depende de las regiones geográficas y varía de acuerdo a los grupos étnicos, se ha registrado que la incidencia anual oscila entre 2-13/100.000 habitantes. Las tasas más bajas se han registrado en habitantes de raza negra de Zimbawe y América, así como en España e India. La más alta de incidencia en el mundo se encuentran en Chile, además, en el noreste de Europa, Israel, indios americanos y americanos de origen mexicano.

Recientes estudios sugieren que el gen de CDKN2, también conocido como MTS1 o p16INK4, contribuye de manera importante en la génesis del cáncer de vesícula biliar (Lazcano-Ponce, y otros, 2001)Se han registrado alteraciones genéticas vinculadas con los genes K RAS y P53 en el cáncer de vesícula biliar.

Los pólipos vesiculares de tamaños mayores a $10 \mathrm{~mm}$ de carácter sésiles e iso o hipoecogenicos en ultrasonografía conllevan el más alto riesgo de degeneración y cáncer de vesícula biliar (Bouchentouf, y otros, 2011). Se ha observado una correlación con la vesícula en porcelana y la colelitiasis en el desarrollo de cáncer de vesícula biliar (Lazcano-Ponce, y otros, 2001).

En estudios revisados la infección por especies de Helicobacter y Salmonella typhi y paratyphi se ha encontrado como factor de riesgo en el desarrollo de cáncer de vesícula biliar (Lazcano-Ponce, y otros, 2001). Se han encontrado evidencias que existe un mayor riesgo de cáncer de la vesícula en trabajadores en las áreas de aceites, papel, textiles, químicos, zapatos, acetato de celulosa y el radón.

Las neoplasias de la vesícula biliar son en gran mayoría adenocarcinomas (95-98\%). Otros tipos histológicos son carcinoma es-

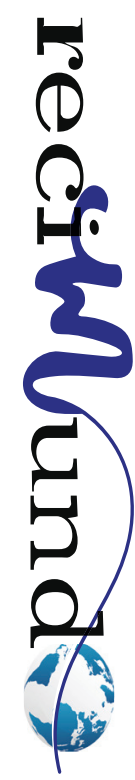


camoso puro, rabdomiosarcoma embrionario, carcinoide, tumor de células granulosas, carcinosarcomas, y tumores de estirpe hematopoyética o linfática (Andrew, y otros, 2010). El cáncer de vesícula biliar se ha fraccionado en metaplásico y no metaplásico, enfocándose en la ausencia o no de cambios histológicos de la secuencia metaplasia-displasia-carcinoma in situ en la mucosa vesícular neoplásica y adyacente al tumor (Andrew, y otros, 2010).

Según su aspecto macroscópico, los tumores de la vesícula biliar pueden clasificarse, en infiltrantes, papilares o nodulares, de acuerdo a la forma de crecimiento en el interior de la vesícula biliar (Bartlett, Fong, \& Fortner, 1996).

Los carcinomas de vesícula biliar se localizan en el cuello (10\%), seguido por orden de frecuencia del cuerpo (30\%) y la mayor parte en el fondo vesícular (60\%), en existen casos que afecta la vesícula biliar en su totalidad (Andrew, y otros, 2010).

Las vías de diseminación tumoral del cáncer de vesícula biliar son; intraperitoneal, neural, linfática, vascular, intraductal y directa. Estos tumores tienden a la invasión locorregional intraperitoneal o a distancia. El hígado es el órgano más frecuentemente afectado tanto en invasión por contigüidad como metastásica (Barlett \& Fong, 2000).

\section{Epidemiología y Clínica}

El cáncer de la vesícula biliar es el más usual de los tumores del árbol biliar y el quinto cáncer más común del tracto digestivo (Randi, Malvezzi, Levi, \& et al, 2009). Se manifiesta en edades avanzadas y es más frecuente en mujeres que en hombres en una relación de tres a cuatro veces. Este tumor se ha vinculado a factores como la existencia de litiasis vesicular (80-90\% de los pacientes con cáncer presentan colelitiasis), el hecho de que los conductos pancreático y la vesícula en porcelana y biliar presenten una desembocadura común. En un adenocarcinoma termina el $80 \%$ de los casos, los más inusuales el carcinoma escamoso, carcinoma de células pequeñas, cistoadenocarcinoma y adenoacantomas.

Los tumores de la vesícula biliar pueden desarrollarse en una presentación clínica de cuatro posibles escenarios:

- En sospecha clínica por los síntomas del paciente;

- En un hallazgo incidental con una técnica de imagen abdominal realizada en búsqueda de un diagnóstico diferencial;

- En hallazgo incidental durante una cirugía de colecistectomía por presunta patología benigna;

- En hallazgo incidental en la pieza quirúrgica después de la colecistectomía simple.

El diagnóstico clínico más común, es el que se distingue de la patología benigna de la vesícula incluyendo el cólico biliar y la colecistitis aguda. Asimismo, el 50\% de los pacientes con tumores de vesícula son diagnosticados antes de la cirugía (Duffy, Capanu, Abou-Alfa, \& et al, 2008). La ictericia por obstrucción del conducto hepático común puede ser producida por crecimiento del tumor. Desafortunadamente, la clínica analítica de laboratorio suele ser normal en las fases iniciales. Los marcadores tumorales CEA y CA 19-9 se presentan elevados pero no son conclusivos para el diagnóstico diferencial ya que sensibilidad y especificidad no es relevantes.

El pronóstico es incierto en los pacientes diagnosticados antes de la cirugía; puede verse afectado por los estadios avanzados de la enfermedad. Cuando el hallazgo es casual en piezas de colecistectomía ocurre lo contrario. (De Aretxabala, Roa, Burgos, \& et al, 1997). El factor pronóstico más importante es el estadio patológico y la única esperanza curativa es la opción quirúrgica. (Arnaud, Casa, Georgeac, \& et al, 1995), (De Aretxabala, Roa, Burgos, \& et al, 1997). 
Los síntomas dominantes en esta revisión fueron dolor abdominal, ictericia y masa palpable en el hipocondrio derecho; además el 14\% presentó antecedente de ictericia + coluria + acolia y unos pocos fiebre con escalofríos. Se encontró que la frecuencia en mujeres es más alta que en hombres y de manera característica en mayores de cincuenta años: 59,5 años en promedio (rango 40-80). (Aretxabala, Roa, Burgos, \& et al, Cáncer inaparente de la Vesícula Biliar, 2001).

La información de laboratorio y la imagenología tiende a concluir el diagnóstico clínico de la enfermedad, sólo en etapa muy avanzada e incurable, por tal motivo, para la enfermedad temprana, con lesiones potencialmente curables no son útiles. (Aretxabala, Roa, Burgos, \& et al, Cáncer inaparente de la Vesícula Biliar, 2001), (Arroyo, GETICS Cáncer de vesícula biliar Artículo de revisión Grupo de Estudio, Tratamiento e Investigación del Cáncer del Sur).

Se recomienda ante cualquier duda durante la cirugía, la colecistectomía abierta en caso de sospecha en el preoperatorio y biopsia extemporánea. (V, (Cubillos, Duarte, Quappe, \& et al, Cáncer de vesícula biliar. Estudio anatomo clínico de 100 casos, 1987) (Yagamuchi, Chijiiwa, Saiki, \& et al, 1997). Algunos autores sugieren la vía laparoscópica ante la sospecha pre-operatoria del carcinoma, con la precaución de extraer la vesícula con una bolsa para evitar la metástasis por diseminación en el sitio por donde es retirada la vesícula, de igual manera, se debe considerar el tratamiento del sitio de los trocares con radioterapia posteriormente a la laparoscópica. (Fong, Brennen, Turnbull, \& et al, 1993), (Clair, Lautz, \& Brooks, 1993), (Ohtami, Takano, \& Shirai, 1998), (Reddy \& Sheridan, 2000), (Ricardo, Freig, Ellis, \& et at, 1997), (Shirai, Ohtami, \& Hatakayama, 1997).

Dependiendo de la fase de la enfermedad en el caso de un hallazgo accidental de carcinoma de la vesícula después de una colecistectomía se pudiese realizar una segunda intervención más radical. (Ogura, Mizumoto, Isaji, \& et al, 1991). Para las lesiones T2-T4, se debe considerar una cirugía complementaria después de realizar estudios imagenológicos para definir la diseminación de la enfermedad. (Gall, Kockerling, Scheele, \& et al, 1991). Para los casos T1, no se requiere ninguna cirugía extensa debido a que el pronóstico es bueno y no se justifica la morbilidad de la cirugía más radical. (Fong, Jarnagin, \& Blumgart, Gallbladder cancer: comparison of patients presenting initially for definitive operation with those presenting after prior non curative intervention, 2000). No se ha utilizado quimioterapia o radioterapia de manera rutinaria ante un tumor, resecable o no, y no hay por tanto un consenso al respecto. (Aretxabala, Roa, Burgos, \& et al, Preoperative chemo radiotherapy in the treatment of gallbladder cancer , 1999). 
Tabla 1. Criterios para Etapificación del cáncer de vesícula biliar

\begin{tabular}{|c|l|}
\hline \multicolumn{2}{|c|}{ Tumor primario $(T)$} \\
\hline Tx & Tumor primario no puede ser evaluado \\
\hline T0 & Sin evidencia de tumor primario \\
\hline Tis & Carcinoma in situ \\
\hline T1 & Tumor invade la lámina propria o la capa muscular \\
\hline T1a & Tumor invade la lámina propia \\
\hline T1b & Tumor invade la capa muscular \\
\hline T2 & $\begin{array}{l}\text { Tumor invade el tejido conectivo perimuscular sin extensión más allá de la } \\
\text { serosa o dentro del hígado. }\end{array}$ \\
\hline & $\begin{array}{l}\text { Tumor perfora la serosa (peritoneo visceral) y/0 directamente invade el hígado } \\
\text { y/u otro órgano adyacente o estructura como el estómago, duodeno, colon, } \\
\text { páncreas, omento o conductos biliares extrahepáticos. }\end{array}$ \\
\hline T4 & $\begin{array}{l}\text { Tumor invade la vena porta o la arteria hepática o invade dos o más órganos } \\
\text { extrahepáticos o estructuras Linfonodos regionales (N) }\end{array}$ \\
\hline
\end{tabular}

\begin{tabular}{|l|l|}
\hline \multicolumn{3}{|c|}{ Nx Linfonodos regionales no pueden ser evaluados } \\
\hline N0 & Sin metástasis en linfonodos regionales \\
\hline N1 & Metástasis en linfonodo regional \\
\hline N2 & $\begin{array}{l}\text { Metástasis en linfonodos periaórticos, pericavos, de arteria mesentérica } \\
\text { superior y/o del tronco celiaco }\end{array}$ \\
\hline
\end{tabular}

\begin{tabular}{|l|l|}
\hline \multicolumn{2}{|c|}{ Metástasis a distancia (M) } \\
\hline M0 & Sin metástasis a distancia \\
\hline M1 & Con metástasis a distancia \\
\hline
\end{tabular}

\begin{tabular}{|l|l|}
\hline \multicolumn{2}{|c|}{ Grado Histológico } \\
\hline GX & Grado no puede ser evaluado \\
\hline G1 & Bien diferenciado \\
\hline G2 & Moderadamente diferenciado \\
\hline G3 & Pobremente diferenciado \\
\hline G4 & Indiferenciado \\
\hline
\end{tabular}

Fuente: Autores 2020

\section{Etiología y Factores de Riesgo}

La etiología exacta del CVB aún no ha sido tipificada. Sin embargo, los principales factores de riesgo sistematizados en el desarrollo de CVB han sido la colecistolitiasis crónica de larga data y el género femenino entre de otras variables.

En un estudio se observó que el 99\% de los tumores malignos de la vesícula biliar son originados en el epitelio y de estos, son adenocarcinomas el 95\%. Algunos factores de riesgo que han sido estudiados, se asocian estrechamente con el CVB que intervendrían de forma variable en la patogenia de los tumores malignos.

Todos los estudios han reportado que en pacientes con cálculos en la vesícula biliar 
de más de $3 \mathrm{~cm}$ de diámetro, el riesgo de desarrollar CVB es diez veces mayor que en pacientes con cálculos menores a $1 \mathrm{~cm}$ de diámetro (Diehl, Epidemiology of gallbladder cancer: a synthesis of recent data, 1980). Además, han concluido una gran vinculación entre CVB y la colelitiasis. Es excepcional la presencia de este cáncer en ausencia de litiasis. En el caso de Chile la prevalencia de colelitiasis es de $50 \%$ a la edad de 50 años, esto demuestra la alta incidencia de CVB (De Aretxabala X. , 2007). Los factores de riesgo aumentan progresivamente con la edad, siendo la edad de hallazgo más frecuente entre los 65-75 años, y más común en el sexo femenino (Lazcano-Ponce, y otros, 2001), detectándose mayor riesgo durante la edad fértil y menor riesgo en el período posmenopáusico, vinculando un efecto importante de los estrógenos. Esto ha sido descrito por diversos autores, que además determinaron un mayor riesgo de CVB asociado con menopausia tardía, menarquía precoz, múltiples embarazos. Por otro lado, la terapia de reemplazo hormonal se ha relacionado a un mayor riesgo de cáncer de vesícula y a un aumento de la litiasis vesicular.

El factor de riesgo más importante para el cáncer de vesícula biliar es la litiasis vesicular (Andia, Gederlini, \& Ferreccio, 2006). Aunque no se ha podido demostrar una relación causa efecto absoluta, se trata del principal factor de riesgo vinculado con el CVB (Zatonski \& et al, 1993).

Un estudio registro que los pacientes con litiasis suelen tener un riesgo relativo de 2,4 de cáncer de vías biliares si el lito tenía un tamaño de 2 a $2,9 \mathrm{~cm}$ y un riesgo relativo mayor de 10,1 si el lito medía 3 o más centímetros, (Diehl, Gallstone size and the risk of gallbladder cancer, 1983). La litiasis desencadenaría una respuesta inflamatoria continua con liberación de factores de crecimiento (promotores tumorales). Estos ejercerían su efecto sobre un epitelio previamente dañado por agentes que producen alteraciones en genes como p-53, el K-ras, el Bcl-2, el MAPK y otros.

Los pacientes portadores crónicos de Salmonella typhi y paratyphi incrementan su riesgo de desarrollar neoplasia; la producción de sustancias carcinogénicas desarrolladas por microorganismos como Clostridium aislado en la bilis de pacientes portadores de litiasis. (Welton \& et al, 1979). La observación de que en vesículas resecadas con estas alteraciones el 83, 13,5 y 3.5 $\%$ presenta displasia, hiperplasia atípica y carcinoma in situ, lesiones consideradas precursoras del cáncer invasor. Es favorecida por la hipótesis de la litiasis vinculada a inflamación como promotor de cáncer de vías biliares.

Asimismo, se ha evidenciado una relación más estrecha con los cálculos de colesterol, y con el tiempo de evolución de la colelitiasis. (Diehl, Gallstone size and the risk of gallbladder cancer, 1983). Sin embargo, estudios autópsicos han puesto de manifiesto que el riesgo de desarrollar CVB en pacientes con colelitiasis es del $1 \%$, aunque viceversa, el $70 \%$ de los hallados en pacientes con CVB son pacientes de colesterol; por otro lado, la incidencia de CVB en una población de portadores de litiasis oscila entre el 0,3 y el $3 \%$. Por las referencias expuestas son demasiado bajas como para considerar la litiasis como el único factor carcinogénico directo. (Hart \& et al, 1971).

Diversos estudios revelan que, tanto la unión pancreatobiliar anómala que causa inflamación crónica, como la vesícula de porcelana que se obtiene de la calcificación sobre una inflamación crónica, están vinculadas al incremento del riesgo de cáncer de vesícula. (Curley \& et al, 2000). Los adenomas de vesícula biliar se describen como hallazgos incidentales entre el 0,15 y el $8 \%$ de las colecistectomías (Kozuka \& et al, 1982). De manera esporádica se ha evidenciado la vinculación del CVB con la colitis ulcerosa, algunas formas de parasitosis y el humo del

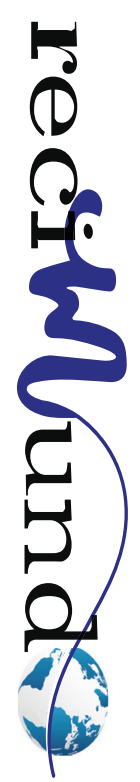


tabaco, además el tamaño está directamente relacionado con potencial de malignización, por lo tanto, esos adenomas reconocidos en estudios ecográficos < 1 supondrán indicación de colecistectomía.

\section{Anatomía patológica}

Es cierto que, las neoplasias de la vesícula biliar son adenocarcinomas (95-98\%), el $75-80 \%$ de los adenocarcinomas poseen formas diferenciadas de las neoplasias. El adenocarcinoma papilar, es el único tipo histológico con un pronóstico favorable en cuanto a supervivencia del paciente se refiere, por otro lado, los carcinomas "oat cell" los adenoescamosos son las formas con peor pronóstico. Otros tipos histológicos serían: rabdomiosarcoma embrionario; carcinoide; carcinosarcomas, carcinoma escamoso puro; tumor de células granulosas y tumores de estirpe hematopoyético o linfático (Gers, 1961).

El tiempo promedio de progresión se ha estimado en 15 años en las lesiones precursoras a cáncer invasivo (5 años entre la displasia y el carcinoma in situ y 10 años más entre el cáncer in situ y el invasivo).

Según su aspecto macroscópico, los tumores de la vesícula biliar pueden clasificarse, en infiltrantes (comunes). Los papilares 0 nodulares en función de la forma de crecimiento en el interior de la vesícula biliar. (Sumiyoshi \& et al, 1991).

El hígado es el órgano más afectado (entre el 40 y el 60\%), siendo invadido por contigüedad como metastásica. Así mismo, estos tumores tienden más a la invasión regional que intraperitoneal o a distancia fuera del abdomen, la vía más importante por la que el CVB hace metástasis hepáticas es la expansión angiolinfática a través de los pedículos portales glissonianos desde las áreas de infiltración hepática directa (Ohtsuka \& et al, 1998)

\section{Diagnostico}

El diagnóstico del cáncer de vesícula biliar es tardío. La detección temprana de esta patología es difícil. Los síntomas son poco específicos, el síntoma que se muestra con más recurrencia es el dolor de tipo visceral, sordo, profundo, persistente, sin exacerbaciones y localizado en el hipocondrio derecho. Los otros síntomas que se suelen presentar son ictericia, síndrome tóxico paraneoplásico y presencia de masa palpable en hipocondrio derecho. La etapificación actual del CVB se rige principalmente según el sistema TNM (tumour-node-metastasis) (Tabla1 - Tabla 2) (AJCC 2010).

En los pacientes con tumores avanzados localmente que presentan ictericia secundaria a infiltración de la vía biliar principal, los exámenes de laboratorio no van a mostrar alteraciones específicas, el perfil hepático puede ser colestasico, en algunos casos se presenta anemia y leucocitosis. Los niveles séricos de antígeno carcinoembrionario (CEA) y CA19-9 han sido estudiados como marcadores tumorales de cáncer de vesícula (Furlan, Ferris, Hosseinzadeh, \& Borhani, 2008) (Gore \& Shelhamer, 2007). 
Tabla 2. Etapificación del cáncer de vesícula biliar

\begin{tabular}{|c|c|c|c|}
\hline \multicolumn{4}{|c|}{ Etapificación } \\
\hline 0 & Tis & N0 & M0 \\
\hline I & T1 & N0 & M0 \\
\hline II & T2 & N0 & M0 \\
\hline IIIA & T3 & N0 & M0 \\
\hline IIIB & T1-3 & N1 & M0 \\
\hline IVA & T4 & N0-N1 & M0 \\
\hline IVB & $\begin{array}{c}\text { Cualquier } \\
\text { T }\end{array}$ & N2 & M0 \\
\hline & $\begin{array}{c}\text { Cualquier } \\
\text { T }\end{array}$ & $\begin{array}{c}\text { Cualquier } \\
\mathrm{N}\end{array}$ & $\mathrm{M} 1$ \\
\hline
\end{tabular}

Fuente: Autores 2020

En mujeres sobre 40 años, la ecografía se debe realizar en los grupos de alto riesgo, se recomienda como método de pesquisa ampliamente utilizado, siendo este de muy bajo costo, no es invasivo y es de fácil acceso para todos los estratos socio-económicos de la población.

El cáncer de vesícula biliar se puede descubrir con la ecografía abdominal cuando es una masa voluminosa que ocupa el lecho vesicular o bien cuando se trata de una masa polipoidea. Con respecto, a lesiones de pequeñas dimensiones y estadios iniciales suelen ser hallazgos casuales durante el examen ecográfico orientado por sospecha de colelitiasis. Otros descubrimientos ecográficos vinculados al cáncer de vesícula biliar son; engrosamiento de la pared vesicular, irregularidades parietales con presencia de submucosa hipoecoica e hídrops vesicular en proporción con la masa que obstruye el infundíbulo vesicular.

La ecografía es muy sensible identificar dilatación de la vía biliar intra y/o extrahepática y la presencia de lesiones metastásicas hepáticas o infiltración directa del parénquima de los segmentos IVb y V (Furlan, Ferris, Hosseinzadeh, \& Borhani, 2008)(Gore \& Shelhamer, 2007). La ecografía-Doppler permite analizar los flujos arteriales y porta- les de los elementos del hilio hepático permitiendo identificar pacientes con cáncer de vesícula biliar no resecable por invasión tumoral de estas estructuras. Utilizando ambos métodos ecográficos se puede llegar a detectar la invasión portal en hasta el 83$86 \%$ de los casos (Furlan, Ferris, Hosseinzadeh, \& Borhani, 2008) (Gore \& Shelhamer, 2007).

La tomografía axial computarizada es el método más sensible y rentable para estudiar los casos en los que se sospecha cáncer de vesícula biliar. Pudiendo detectar una masa que ocupaba la luz de la vesícula biliar, una masa polipoidea y un engrosamiento difuso de la pared vesícular. Permitiendo valorar la profundidad de la infiltración del parénquima hepático en los cánceres avanzados, la presencia de lesiones metastásicas intrahepáticas, infiltraciones a la vía biliar principal, dilatación del sistema biliar intrahepático y el nivel obstrucción del mismo.

La tomografía axial helicoidal en fase dual es de gran utilidad en el diagnóstico de las metástasis ganglionares del cáncer de vesícula biliar, ya que permite evaluar la presencia de infiltración de estructuras vasculares mayores (Gore \& Shelhamer, 2007).

La resonancia magnética nuclear es de utili-

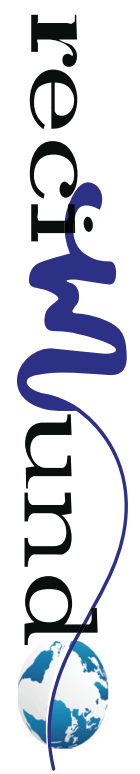


dad para la valoración de la anatomía biliar, hepática y pancreática. Se determina la colangiopancreato resonancia (Furlan, Ferris, Hosseinzadeh, \& Borhani, 2008).

La arteriografía del tronco celíaco y la mesentérica superior con retorno venoso portal es una prueba que se hace de forma selectiva por algunos grupos muy concretos, existen técnicas menos invasivas que suministran información altamente sensible y específica de la relación de las neoplasias vesículares con las estructuras vasculares hiliares y del ligamento hepatoduodenal. La punción y aspiración con aguja fina muestra la confirmación del diagnóstico histológico de masas vesículares no resecables. El examen citológico de la vía biliar también se ha empleado. La ultrasonografía endoscópica contribuye al diagnóstico de extensión y estadificación de las neoplasias biliares.

\section{Tratamiento}

Se debe considerar, en la planificación del tratamiento la etapificación de la enfermedad, ya que existen pacientes con cáncer inaparente desde el punto de vista clínico, son aquellos que se presentan como colelitiasis, sin sospecha de enfermedad tumoral maligna, en quienes la biopsia postoperatoria revela la presencia del tumor. En diversos casos la colecistectomía, puede ser curativa. Otro grupo se presenta como localmente avanzado, comprometiendo el lecho hepático y la eventual presencia de adenopatías sospechosas. En los pacientes con presencia intraoperatoria de metástasis se debe continuar con la cirugía radical. Se planifican terapias paliativas para el grupo de pacientes con enfermedad metastásica, cuyo enfoque terapéutico debe orientarse a la confirmación histológica del tumor y de las lesiones metastásicas. Finalmente, las medidas terapéuticas están determinadas, como hemos señalado previamente, por la etapa del CVB.

Resección quirúrgica. En el presente la resección quirúrgica radical con fines curativos es aceptada el único método de alcanzar en los pacientes con CVB tasas de supervivencia. La resección radical persigue la ausencia de tumor residual tras la intervención quirúrgica; para ello se ha instaurado tres categorías en función del resultado obtenido: RO (ausencia de tumor residual micro y macroscópico); RI (presencia de tumor residual microscópico), y R2 (presencia de tumor residual macroscópico). La resección radical $\mathrm{RO}$ se realiza en un porcentaje variable de pacientes que oscila entre el 20 y el 50\%; esto varía dependiendo de la selección preoperatoria de los enfermos que van a ser sometidos a laparotomía y de la propia experiencia del cirujano.

La colecistectomía laparoscópica es el procedimiento típico para el tratamiento de la litiasis biliar sintomática (Kokudo, Makuuchi, \& Natori, 2003). Con su aparición han tomado interés y relevancia varios conceptos: cáncer de vesícula biliar incidental; la neoplasia vesicular no sospechada pre o intra operatoria es diagnosticada por el patólogo en el análisis del espécimen de colecistectomía (Bouchentouf, y otros, 2011)

La identificación de pacientes portadores de litiasis biliar sintomática para someterlos a colecistectomía y el análisis exhaustivo histopatológico de los especímenes de colecistectomía para diagnosticar aquellos tumores incidentales en estadios iniciales que van a ser subsidiarios de re-intervención con intención benéfica. Los resultados son basados mayoritariamente en la cirugía de resecciones de primera intención con finalidad curativa (Bartlett, Fong, \& Fortner, 1996) (Hueman, Vollmer, \& Pawlik, 2009).

Los criterios de irresecabilidad del cáncer de vesícula biliar son: presencia de metástasis hepáticas, peritoneales o a distancia; afección extensa del tronco principal de la vena porta o de la arteria hepática, y afección bilateral de ambas ramas portales 0 arteriales, (Kokudo, Makuuchi, \& Natori, 
2003).

Cuando el tumor infiltra la capa muscular sin sobrepasarla (T1b) se recomienda la colecistectomía radical extendida. La colecistectomía simple sólo puede considerarse para los pacientes con cáncer incidental descubierto en el examen histológico postoperatorio y estadio T1a.

Los pacientes con tumores T2 deben tratarse siempre con colecistectomía radical extendida, colecistectomía ampliada a 2 $\mathrm{cm}$ de margen del lecho vesicular y esqueletización ganglionar del epiplón menor, y consiste en realizar en bloque una colecistectomía y bisegmentectomía IVb y $\mathrm{V}$ (Bouchentouf, y otros, 2011).

El tratamiento quirúrgico del cáncer de vesícula localmente avanzado (tumores T3 y T4) requiere realizar resecciones hepáticas y de órganos vecinos más o menos extensas que se acompañan de tasas de morbimortalidad no despreciables.

La única variante terapéutica que debe acompañar a la re resección del cáncer de vesícula biliar incidental cuando la colecistectomía se realizó por laparoscopia es la resección radical de los puertos de entrada de los trocares (Kokudo, Makuuchi, \& Natori, 2003) (Shimizu, Arima, \& Yokomuro, 2006).

Asimismo, los pacientes con sospecha preoperatoria de CVB deben someterse a cirugía abierta con intención curativa y radical en un solo tiempo; igualmente, aquellos en los que el CVB se descubre de forma intraoperatoria durante el procedimiento laparoscópico deben ser convertidos a cirugía abierta para llevar a cabo la intervención definitiva con intención curativa. (Bartlett, Fong, \& Fortner, 1996).

Quimioterapia. Al respecto de este tratamiento en la CVB, se observa el planteamiento de tres autores, quienes concluyen que su efecto no aumenta necesariamente la supervivencia o su efecto es muy leve.

- La quimioterapia se ha usado como terapia coadyuvante en el CVB resecado o como paliación del CVB no resecable, y no se ha logrado aumentar la supervivencia en ningún casos (Lee, Jin-Young, Chang-Sup, Kang, \& Sun-Whe, 2011).

- Diversos estudios cooperativos han examinado el papel de la mitomicina C (en bolos), fluorouracilo, adriamicina y nitrosureas, solos o en combinación, con comunicaciones aisladas de mínimas respuestas (Taal \& et al, 1993).

- Por último se puede mencionar que la terapia regional intraarterial con mitomicina $\mathrm{C}$ también ha sido usada, con tasas globales de respuesta del $48 \%$ y un incremento de la mediana de supervivencia de 5 a 14 meses en relación con cohortes históricas de control. (Makela \& Kairaluoma, 1993).

Radioterapia. Las distintas aplicaciones de radioterapia (externa, intraoperatoria e interna, esta última utilizando dispositivos insertados por vía percutánea o endoscópica que liberan la radiación localmente mediante agujas de iridio-192 o de cobalto-60) se han utilizado como una terapia paliativa para el cáncer de vesícula biliar localmente avanzado y no resecable; aunque el beneficio es escaso (de 6 a 8 meses en la mediana de supervivencia) los resultados sugieren que podría aumentar la sobrevida. No obstante, es bien tolerada y podría ser útil para mejorar los síntomas en pacientes (Houry \& et al, 1989) (Andrew, y otros, 2010).

Recientemente, hay publicaciones de dos series de cirugía vinculada a radioterapia intraoperatoria para CVB avanzado, con tasas de SV de 10,3\% a 3 años en uno de ellos. El estudio investigativo de esta línea terapéutica podría aportar calidad y cantidad de vida a los sujetos con CVB localmente avanzado. (Busse \& et al, 1991). 


\section{Morbimortalidad}

Debido a la complejidad técnica, tiempo quirúrgico empleado y a la eventual necesidad de derivados sanguíneos, la cirugía con intención curativa del CVB se acompaña de una morbilidad postoperatoria no despreciable, con tasas que oscilan entre el 5-54\%. Las complicaciones más comunes serán fístulas biliares, insuficiencia hepática levemoderada, absceso intraabdominal e insuficiencia respiratoria. La mortalidad postoperatoria de los casos operados y resecados oscila, en función de las series, entre el 0 y el $21 \%$, siendo mayor cuando se realizan resecciones hepáticas mayores y resecciones de la vía biliar.

La supervivencia a 5 años de los pacientes con cáncer de vesícula biliar a los que se les realiza cirugía radical curativa adecuada en función de su estadio tumoral se sitúa entre el 14 y el $20 \%$.

\section{Conclusion}

No se justifica una re-operación en pacientes etapa T1b, es decir, con infiltración tumoral hasta la capa muscular. Ya que la sobrevida en estos pacientes es altísima, sobre $90 \%$ a 5 años. Una vez realizada la colecistectomía se diagnostica el carcinoma temprano de la vesícula biliar en la inmensa mayoría de los pacientes.

Aunque el cáncer de la vesícula biliar es una entidad de baja frecuencia en la población, es la quinta neoplasia maligna gastrointestinal y la más común del tracto biliar, es raro, predomina en el sexo femenino y se acompaña con frecuencia de obstrucción biliar. En la revisión constatamos que está asociada a litiasis vesicular, obesidad, pólipo vesícula y sin antecedentes patológicos familiares.

En la actualidad, existen avances tecnológicos modernos, el diagnóstico suele ser tardío; eventualmente es un descubrimiento casual durante la colecistectomía mediante el examen anatomopatológico de la pieza operatoria. Asimismo, dado que la sobrevida es muy baja a pesar de que existen diversas alternativas terapéuticas, la cirugía sigue siendo la única alternativa de curación en estadios tempranos ayudando a mejorar la calidad de vida en etapas avanzadas.

El pronóstico en los pacientes con enfermedad irresecable, es parecido al cáncer de páncreas, con una supervivencia media de 5-9 meses. Aun cuando, puede hacer la resección, la supervivencia a los 5 años oscila entre el 25 y el $55 \%$.

Se propone la necesidad de realizar nuevos estudios e investigaciones de diagnóstico temprano, para sistematizar características de la fisiopatología, para que el CVB pueda ser tratado en forma oportuna en relación con múltiples marcadores bioquímicos y en biopsias de grasa.

\section{Bibliografía}

Arroyo, G. (s.f.). GETICS Cáncer de vesícula biliar, Tratamiento e Investigación del Cáncer del Sur (Vol. VIII). Argentina: Oncología clínica.

Chan, C., Chang, H., Chen, Y., Yang, L., Chen, S., Kuo, S., \& et al. (2003). A 10-year experience of unsuspected gallbladder cancer after laparoscopic cholecystectomy (Vol. 88). Int Surg.

Cubillos, L., Duarte, I., Quappe, G., \& et al. (1987). Cáncer de vesícula biliar. Estudio anatomo clínico de 100 casos. ChilCir, 39, 201-7.

Diehl, A. (1990). Epidemiology of gallbladder cancer: a synthesis of recent data (Vol. 65). JNCl.

Gers, P. (1961). Primary carcinoma of the gallbladder: a thirty years summary (Vol. 153). Ann Surg.

Malvenda, F. (2002). Cáncer de la vesícula biliar. Resultados de la cirugía resectiva (Vol. 54). Chil Cir.

Marijuán, \& et al. (1992). Carcinoma primario de vesícula biliar. Revisión de 41 casos. Esp Enf Digest, 82, 169-71.

Potente, F., \& et al. (1994). Il carcinoma della colecisti, La nostra esperienza (Vol. 49). Minerva Chir.

Roa, I., \& et al. (1993). DNA content in gallbladder carcinoma: a flow cytometric study of 96 cases 
(Vol. 23). Histopathology.

Roa, I., Araya, J., Wistuba, I., Villaseca, M., De Aretxabala, X., \& Burgos, L. (1994). Gallbladder cancer in the IX Region of Chile. Impact of the anatomopathological study of 474 cases. Med Chil, 122, 1248-1256.

Shimada, H., Endo, I., Togo, S., \& et al. (1997). The role of lymph node dissection in the treatment of gallbladder carcinoma. Cancer (Vol. 79).

Todoroki, T., Kawamoto, T., Takahashi, H., \& et al. (1999). Treatment of gallbladder cancer by radical resection (Vol. 86). Brit J Surg.

Wanebo, \& al et. (1993). Carcinoma of the gallbladder. J Surg Oncol, 3(Supl), 134-9.

\section{(c) $(\oplus \otimes \odot$ \\ BY NC SA}

RECONOCIMIENTO-NOCOMERCIAL-COMPARTIRIGUAL CC BY-NC-SA

ESTA LICENCIA PERMITE A OTROS ENTREMEZCLAR, AJUSTAR Y CONSTRUIR A PARTIR DE SU OBRA CON FINES NO COMERCIALES, SIEMPRE

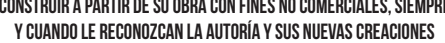
ESTÉN BAJO UNA LICENCIA CON LOS MISMOS TÉRMINOS.

\section{CITAR ESTE ARTICULO:}

Hernández Salcedo, M., Almeida Barba, K., Castillo González, A., \& Freire Sandoval, A. (2020). Diagnóstico y tratamiento de cáncer de vesícula biliar. RECIMUNDO, 4(1(Esp)), 236-249. doi:10.26820/recimundo/4.(1).esp.marzo.2020.236-249 